\title{
Breeding bird community composition in different successional vegetation in the montane coniferous forests zone of Taiwan
}

\author{
Tzung-Su Ding, Huan-Chang Liao, Hsiao-Wei Yuan* \\ School of Forestry and Resource Conservation, National Taiwan University, No. 1, Sec. 4, Roosevelt Road, Taipei 106, Taiwan
}

Received 5 August 2007; received in revised form 20 January 2008; accepted 21 January 2008

\begin{abstract}
To examine the relationship between forest succession following fire and the composition of bird communities, we investigated the vegetation structure, bird population density, foraging behavior and guild structure in bamboo grasslands (11 years since the last fire), pine savanna (41 years), pine woodland (58 years), old-growth hemlock forest (never burned), and old-growth spruce forest (never burned) in the Tatachia area of central Taiwan. Canopy height, total foliage cover, tree density, total basal area of tree, total basal area of snags, foliage height diversity, and tree species richness all increased with successional age. However, shrub cover peaked in intermediate successional stages. The vertical profile of foliage cover was more diverse in later successional forests, which had more breeding bird species and ecological guilds. All the breeding bird species recorded in early and intermediate stages were also found distributed in the late successional forests. Because Taiwan has high precipitation and humidity, and most forest fires in Taiwan are caused by human activities, forest fires and large areas of early successional vegetation were probably rare in the mountain areas of Taiwan prior to the arrival of humans. Therefore, bird species have not had enough time to adapt to areas with early or intermediate successional vegetation. Moreover, late successional forests host all the major plant species found in the early and intermediate stages and have higher foliage height diversity index, which was positively correlated with the bird species richness and bird species diversity index in this study. As a result, all breeding bird species and guilds in the area can be found in late successional forests. Efforts for conserving avian diversity in Taiwan should focus on protecting the remaining native old-growth forests.
\end{abstract}

(C) 2008 Elsevier B.V. All rights reserved.

Keywords: Vegetation succession; Seral stages; Avian assemblages; Ecological guild; Habitat selection; Taiwan

\section{Introduction}

Forest fires abruptly change the structure and composition of biological communities and affect management of forests and biodiversity (Attiwill, 1994). In forest ecosystems, vegetation in later successional stages is usually taller, has more total biomass, and greater tree species richness (e.g., Linder et al., 1997; Cochrane and Schulze, 1999; Wang et al., 2006). Late successional vegetation also tends to have more vertical layers of foliage and higher variance in tree size (e.g., Linder et al., 1997; Venier and Pearce, 2005). These more complex habitats provide greater foraging and nesting opportunities for wildlife (Keller et al., 2003; Díaz et al., 2005; Schwab et al., 2006).

\footnotetext{
* Corresponding author. Tel.: +88623366 4634; fax: +886223654520. E-mail address: hwyuan@ntu.edu.tw (H.-W. Yuan).
}

The species composition of animal communities changes during succession (Oppel, 2006; Schieck and Song, 2006). The conventional view is that, immediately after disturbance, wildlife density and species richness are low (e.g., Venier and Pearce, 2005; Green and Sanecki, 2006; Sarà et al., 2006; Schieck and Song, 2006). However, many studies (e.g., Imbeau et al., 1999; Keller et al., 2003; Pons and Wendenburg, 2005) have found that animal species diversity or total density peaked $0-12$ years after fire or logging. The inclusion of early successional species and cavity-nesting species contributed to these early peaks in density and diversity (Hutto, 1995; Imbeau et al., 1999; Pons and Wendenburg, 2005; Schieck and Song, 2006).

Some wildlife species are restricted to early or intermediate successional stages and do not occur in late successional stages (e.g., Hutto, 1995; Imbeau et al., 1999; Hunter et al., 2001; Herrando et al., 2003; Venier and Pearce, 2005; Paquet et al., 2006). Many animal species associated with early and intermediate successional stages have declined in North 
America and Europe in the past few decades (Brawn et al., 2001; DeGraaf and Yamasaki, 2003). This trend has been attributed to the suppression of natural disturbance and the expansion of agriculture and development (Brawn et al., 2001). To conserve species associated with early and intermediate successional vegetation, biodiversity conservation programs should not suppress natural disturbances (e.g., fire, flood) and, if needed, introduce active anthropogenic disturbances (e.g., prescribed fires, logging) that mimic natural disturbances (Hutto, 1995; Linder et al., 1997; Herrando et al., 2003; Venier and Pearce, 2005; Pons and Wendenburg, 2005; Oppel, 2006; Schwab et al., 2006; Barbaro et al., 2007).

Fires, typhoons, and landslides are the major natural disturbances that occur in Taiwan forests. Due to high annual precipitation (greater than $2500 \mathrm{~mm}$ in $80 \%$ of the area) and steep mountain topography, burned areas in Taiwan are vulnerable to erosion and landslides. Therefore, the policy of forest managers in Taiwan is to suppress all fires (Hwang and Lin, 2005). In addition, prescribed fires are not used in mountain areas of Taiwan. Nevertheless, due to increased human activities in the last few decades, forest fires are more frequent (Hwang and Lin, 2005), creating more areas of early and intermediate successional stages in the mountains of Taiwan. There have been very few studies of the animal communities associated with the successional vegetation following forest fires in Taiwan.

In this study, we investigated the vegetation structure and the composition of the breeding bird communities in 11-, 41-, and 58-year-old plant communities following forest fires, and in two, primary, old-growth forests in the Tatachia area of central Taiwan. The main objectives of this study were to: (1) determine the species composition of bird communities in vegetation at different successional vegetation; (2) define the ecological guilds for birds and determine their abundance in different successional stages; and (3) examine the relationships between bird community structure and vegetation structure.

\section{Methods}

\subsection{Study site}

We conducted this study in the Tatachia area $\left(23^{\circ} 30^{\prime} \mathrm{N}\right.$, $120^{\circ} 55^{\prime} \mathrm{E}$ ), in central Taiwan. The study site is about 2550 $2850 \mathrm{~m}$ a.s.l. and is on a small mountain range that lies between the Yushan and Alishan mountain ranges (Fig. 1).

Based on weather data from the on-site Luling long-term weather station (2700 $\mathrm{m}$ a.s.1.), the annual average temperature in 2003 and 2004 was $11.2^{\circ} \mathrm{C}$. The highest monthly average temperature was $14.0{ }^{\circ} \mathrm{C}$ (in June), and the lowest monthly average was $4.7^{\circ} \mathrm{C}$ (in January). Annual precipitation at the study site was $4009 \mathrm{~mm}$. About $80 \%$ of the annual precipitation fell in May-September due to the southwest, summer monsoon rains.

In Taiwan, primary forests at this elevation (2550-2850 m) are mainly hemlock (Tsuga chinensis) in xeric habitats, and spruce (Picea morrisonicola) in mesic habitats (Su, 1984). In the study area, grasslands of short bamboo (Yushania niitakayamensis) and silvergrass (Miscanthus transmorrisonensis) usually dominate after forest fires. If no additional fires occur, the bamboo grassland is replaced by pine forests (mainly Pinus taiwanensis and P. armandii) and eventually hemlock or spruce forests. Due to frequent forest fires, there is a mosaic of different vegetation types in the study area.

We established 22 sampling stations in the 5 major vegetation types within the study site: bamboo grassland, pine savanna, pine woodland, hemlock forest, and spruce forest (Fig. 1). All the sampling stations were located in large patches of vegetation (at least $100 \mathrm{ha}$ ) and had similar aspect and elevation (2550-2850 m) (Fig. 1). There were four stations in the bamboo grassland, which represented the first stage of succession after burning. Several fires have burned this site in the past few decades and the last one occurred in January 1993. Intermediate successional vegetation was represented by the pine savanna, burned in 1963, and pine woodland, burned in 1946. There were five stations in each of the forest types. At the time of field sampling, there were virtually no old trees $(>70$ years) and very few snags and logs. The hemlock forest and spruce forest have not experienced forest fire or logging during the last few centuries. Both forests had four stations and represented the late stages of succession. The criteria for selecting sampling stations were: (1) the vegetation structure of the sampling stations was relatively homogeneous; (2) the topography and vegetation of the stations allowed observers to detect birds in all directions; (3) that the stations should be at least $200 \mathrm{~m}$ away from creeks and the edge of different vegetation types; and (4) at least $200 \mathrm{~m}$ away from other sampling stations.

\subsection{Measurement of habitat structure}

We measured 18 habitat attributes (Table 1) at each sampling station from July to October 2004 and grouped them into 3 categories: abiotic, floristic, and physiognomic. For the slope aspect of each station, a relative value from 1 to 16 was given, based on the moisture gradient from the direction of SSW (driest) to NNE (wettest) (Su, 1987). We established a $20 \mathrm{~m} \times 20 \mathrm{~m}$ quadrat at the center of each station and measured the species, height, and diameter at breast height (DBH) of all trees and snags within each quadrat. Foliage cover was measured along two $20 \mathrm{~m}$, randomly oriented transect lines that were orthogonal to each other and passed through the center of each $20 \mathrm{~m} \times 20 \mathrm{~m}$ quadrat. We erected a carbon fiber pole at $0.5 \mathrm{~m}$ intervals along each transect and counted each time the pole made contact with a leaf or branch. The height of each contact was assigned to one of nine vertical layers $(0-0.5 \mathrm{~m}, 0.5-1 \mathrm{~m}, 1-2 \mathrm{~m}, 2-4 \mathrm{~m}, 4-6 \mathrm{~m}$, 6-10 $\mathrm{m}, 10-15 \mathrm{~m}, 15-20 \mathrm{~m}$, and $>20 \mathrm{~m}$ ) and the plant was categorized by one of four growth forms (herb, shrub, subcanopy tree, and canopy tree). There were 80 sample points for foliage cover at each station.

We averaged the foliage cover of each growth form from the number of times the pole touched a branch or leaf of each growth form. A $100 \%$ foliage cover means that the pole touched a branch or leaf once on average. Total foliage cover was 


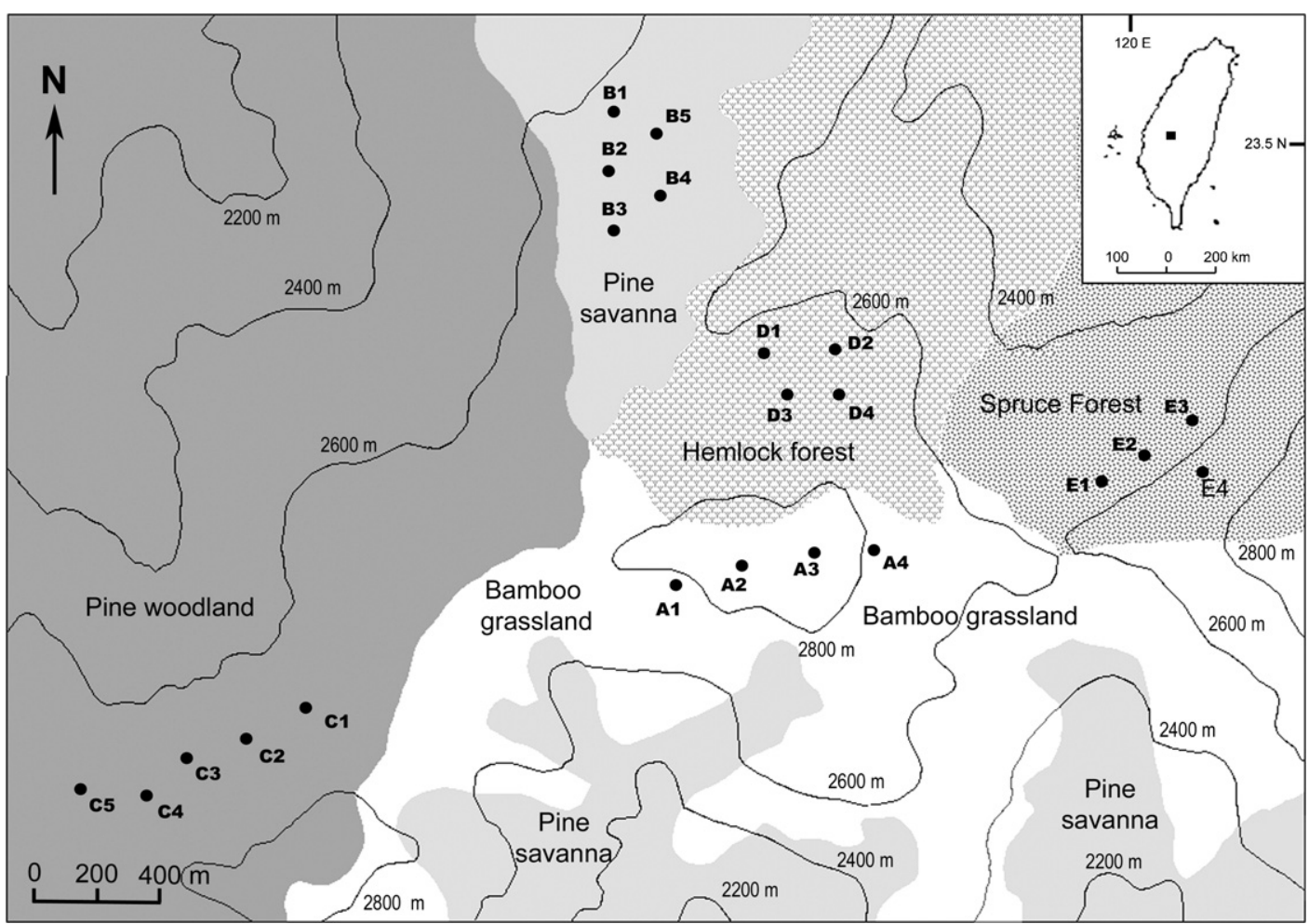

Fig. 1. The study site was located in the montane zone (2550-2850 m a.s.1.) in the Tatachia area of central Taiwan.

summed from the foliage cover of individual growth forms. We used the Shannon-Wiener diversity index (Krebs, 1989) to describe foliage height diversity, using the foliage cover of the nine vertical layers, and tree species diversity, based on the total basal area of each tree species in the $20 \mathrm{~m} \times 20 \mathrm{~m}$ quadrat.

\subsection{Estimating bird density}

Two of the authors (TSD and HCL) estimated the density of each bird species at each station from March to June, 2004 by using the variable-distance circular-plot method (Reynolds

Table 1

The 18 habitat attributes (mean \pm S.D.) of each of the five vegetation types ${ }^{1}$

\begin{tabular}{|c|c|c|c|c|c|}
\hline Habitat attribute & Bamboo grassland & Pine savanna & Pine woodland & Hemlock forest & Spruce forest \\
\hline \multicolumn{6}{|l|}{ Abiotic attributes } \\
\hline Elevation (m) & $2841 \pm 30^{\mathrm{a}}$ & $2682 \pm 5^{b}$ & $2726 \pm 13^{c}$ & $2662 \pm 17^{b}$ & $2627 \pm 22^{\mathrm{d}}$ \\
\hline Aspect & $9.2 \pm 4.2^{\mathrm{a}}$ & $12.6 \pm 3.8^{\mathrm{ab}}$ & $14.2 \pm 1.5^{\mathrm{b}}$ & $10.5 \pm 3.5^{\mathrm{ab}}$ & $12.5 \pm 3.4^{\mathrm{ab}}$ \\
\hline \multicolumn{6}{|l|}{ Physiognomic attributes } \\
\hline Vegetation height (m) & $0.3 \pm 0.5^{\mathrm{a}}$ & $4.8 \pm 1.0^{\mathrm{b}}$ & $11.8 \pm 2.8^{\mathrm{c}}$ & $15.8 \pm 1.5^{\mathrm{d}}$ & $32.0 \pm 2.9^{\mathrm{e}}$ \\
\hline Herb cover $(\%)$ & $89.4 \pm 4.6^{\mathrm{abc}}$ & $99.0 \pm 2.2^{\mathrm{ab}}$ & $69.3 \pm 26.0^{\mathrm{ac}}$ & $46.6 \pm 19.5^{\mathrm{d}}$ & $89.1 \pm 8.6^{\mathrm{abc}}$ \\
\hline Shrub cover $(\%)$ & $15.6 \pm 12.5^{\mathrm{a}}$ & $109.8 \pm 33.2^{\mathrm{b}}$ & $200.8 \pm 51.0^{c}$ & $133.1 \pm 43.3^{\mathrm{b}}$ & $105.9 \pm 25.5^{\mathrm{b}}$ \\
\hline Sub-canopy cover $(\%)$ & $0.0 \pm 0.0^{\mathrm{a}}$ & $50.7 \pm 24.3^{\mathrm{b}}$ & $90.0 \pm 21.0^{\mathrm{b}}$ & $184.4 \pm 41.6^{\mathrm{c}}$ & $141.3 \pm 47.9^{\mathrm{c}}$ \\
\hline Canopy cover $(\%)$ & $0.0 \pm 0.0^{\mathrm{a}}$ & $15.0 \pm 18.8^{\mathrm{a}}$ & $135.3 \pm 60.6^{\mathrm{b}}$ & $123.7 \pm 24.4^{\mathrm{b}}$ & $235.3 \pm 26.4^{\mathrm{c}}$ \\
\hline Total foliage cover $(\%)$ & $105.0 \pm 11.6^{\mathrm{a}}$ & $274.5 \pm 59.4^{\mathrm{b}}$ & $495.4 \pm 48.6^{\mathrm{c}}$ & $487.8 \pm 12.8^{\mathrm{c}}$ & $571.6 \pm 59.3^{\mathrm{d}}$ \\
\hline Proportion of ground foliage $(\%)$ & $100.0 \pm 0.0^{\mathrm{a}}$ & $76.1 \pm 8.3^{\mathrm{b}}$ & $54.5 \pm 7.3^{\mathrm{c}}$ & $36.8 \pm 11.9^{\mathrm{d}}$ & $34.1 \pm 2.6^{\mathrm{d}}$ \\
\hline Tree density (No./ha) & $169 \pm 290^{\mathrm{a}}$ & $1380 \pm 720^{\mathrm{ab}}$ & $1475 \pm 931^{\mathrm{ac}}$ & $1881 \pm 455^{\mathrm{bc}}$ & $4612 \pm 2032^{\mathrm{d}}$ \\
\hline Mean DBH $(\mathrm{cm})$ & $3.1 \pm 4.4^{\mathrm{a}}$ & $6.8 \pm 1.1^{\mathrm{a}}$ & $17.2 \pm 7.1^{\mathrm{b}}$ & $13.9 \pm 3.8^{\mathrm{b}}$ & $6.5 \pm 0.9^{\mathrm{a}}$ \\
\hline $\mathrm{CV}$ of $\mathrm{DBH}(\mathrm{cm})$ & $0.34 \pm 0.55^{\mathrm{a}}$ & $0.93 \pm 0.50^{\mathrm{ab}}$ & $0.75 \pm 0.17^{\mathrm{a}}$ & $1.21 \pm 0.54^{\mathrm{b}}$ & $2.20 \pm 0.37^{\mathrm{c}}$ \\
\hline Total BA of trees $\left(\mathrm{m}^{3} / \mathrm{ha}\right)$ & $0.4 \pm 0.5^{\mathrm{a}}$ & $12.0 \pm 14.5^{\mathrm{a}}$ & $41.8 \pm 14.6^{\mathrm{b}}$ & $64.0 \pm 9.7^{\mathrm{c}}$ & $72.9 \pm 17.4^{\mathrm{c}}$ \\
\hline Total BA of snags $\left(\mathrm{m}^{3} / \mathrm{ha}\right)$ & $0.15 \pm 0.21^{\mathrm{a}}$ & $0.04 \pm 0.08^{\mathrm{a}}$ & $0.83 \pm 0.17^{\mathrm{b}}$ & $29.24 \pm 27.71^{\mathrm{c}}$ & $16.64 \pm 12.09^{c}$ \\
\hline Foliage height diversity & $0.42 \pm 0.23^{\mathrm{a}}$ & $1.52 \pm 0.24^{\mathrm{b}}$ & $1.93 \pm 0.09^{c}$ & $1.98 \pm 0.05^{\mathrm{c}}$ & $2.12 \pm 0.06^{\mathrm{c}}$ \\
\hline \multicolumn{6}{|l|}{ Floristic attributes } \\
\hline Tree species richness & $0.75 \pm 0.96^{\mathrm{a}}$ & $4.80 \pm 1.92^{\mathrm{b}}$ & $6.60 \pm 2.51^{\mathrm{b}}$ & $7.50 \pm 0.58^{\mathrm{b}}$ & $17.50 \pm 4.43^{\mathrm{c}}$ \\
\hline Tree species diversity & $0.06 \pm 0.12^{\mathrm{a}}$ & $0.49 \pm 0.29^{\mathrm{b}}$ & $0.61 \pm 0.27^{\mathrm{b}}$ & $0.76 \pm 0.29^{\mathrm{bc}}$ & $1.10 \pm 0.23^{\mathrm{c}}$ \\
\hline Proportion of broadleaf tree $(\%)$ & $0.0 \pm 0.0^{\mathrm{a}}$ & $1.1 \pm 1.4^{\mathrm{a}}$ & $3.5 \pm 5.9^{\mathrm{a}}$ & $15.6 \pm 8.5^{\mathrm{b}}$ & $27.6 \pm 10.2^{\mathrm{c}}$ \\
\hline
\end{tabular}

\footnotetext{
${ }^{1}$ For each habitat attribute, there were significant differences among vegetation types. The values that are not significantly different $(p>0.05)$ are indicated by
} shared superscript letters. 
et al., 1980), which calculates the average number of individuals recorded within the circular area of a radius that most birds could be effectively detected. The equation for calculating bird density is:

$$
D=\frac{n \times 10^{4}}{\pi r^{2} C},
$$

where $D$ is the estimated density (No./ha) of each species at each station, $n$ is the total number of birds of the species detected within its effective detection radius at the station, $r$ is the effective detection radius $(\mathrm{m})$, and $C$ is the total number of bird counts.

Based on the results of a previous study at this site (Shiu and Lee, 2003), we counted birds at each station for 6 min, which registered more than $80 \%$ of the individuals and species recorded in $30 \mathrm{~min}$ (Shiu and Lee, 2003). The bird counts were only conducted between local sunrise and $3 \mathrm{~h}$ thereafter. We repeated bird counts on all the sampling stations of same vegetation type hourly. At each station, we recorded the number, distance, and sex (by appearance or song if possible) of all birds seen or heard in $6 \mathrm{~min}$. For some secretive species that are difficult to detect visually or by their calls, each record of their territorial songs was treated as two individuals. We excluded individuals that simply flew past the station. In total, we counted birds 30 times at each sampling station and no count was carried out during rain. Both investigators exerted the same sampling effort (15 counts) for each station and had a similar sampling schedule for all the sampling stations. The effective detection radius for each species was determined by inspecting a histogram of bird density in $10 \mathrm{~m}$ concentric bands, following the criteria detailed in Reynolds et al. (1980). Because the detection ability of observers could vary with vegetation structure, the effective detection radius for each species was determined separately for each vegetation type.

Bird nomenclature and taxonomy follows Dickinson (2003), except for that of the Taiwan Bush Warbler (Bradypterus alishanensis), which follows Rasmussen et al. (2000). We calculated bird species diversity by applying the ShannonWiener diversity index (Krebs, 1989) to the density of each bird species. Total bird biomass was summed from the product of the density and biomass (reported in Shiu et al., 2005) of each bird species.

\subsection{Resource utilization of birds}

We directly observed bird foraging behavior from May to July 2004, to determine the food resource utilization of the bird species recorded. One author (HCL) closely followed the first bird encountered in the sampling stations and recorded its successful foraging behaviors until the bird flew out of sight. Recorded variables included food item (nectar, fruit, seed, bud, invertebrate, vertebrate, and carrion), foraging substrate (ground, shrub, tree leaves, bole, and air), and foraging tactic (glean, fly-catch, hawk, and peck). When the focal bird was no longer in sight, the next bird encountered would be followed. A total of $90 \mathrm{~h}$ of observation time was spent in the study site
(18 $\mathrm{h}$ in each of the five major vegetation types). For those bird species with less than 20 records of successful foraging behavior (14 species in total), we included our previous observations during breeding seasons in the study site to prepare the foraging behavior data for guild classification.

\subsection{Statistical analyses}

We used cluster analysis to classify the ecological guilds of birds by foraging behavior and to group sampling stations by bird species composition. We used Euclidean distance for similarity calculations and UPGMA (unweighted pair-group method using arithmetic averages) for the linkage method in cluster analysis. We employed PC-ORD 4.25 (McCune and Mefford, 1999) to conduct cluster analysis and DCA (Detrended Correspondence Analysis) and SPSS 12.0 for ANOVA and regression analyses.

\section{Results}

\subsection{Habitat structure}

There were significant differences in all 18 habitat attributes among at least some of the 5 major successional stages (Dunn test, $p<0.05$; Table 1). Most physiognomic and floristic attributes increased with successional stage (canopy height, sub-canopy cover, canopy cover, total foliage cover, tree density, CV of DBH, total basal area of tree, total basal area of snag, foliage height diversity, tree species richness, and tree species diversity). In contrast, shrub cover peaked in intermediate successional stages, and the relative proportion of ground foliage (herb and shrub) peaked in bamboo grassland and then decreased with successional age. The vertical profile of foliage cover was most even in pine woodland, hemlock forest, and spruce forest (Fig. 2). Most foliage in bamboo grassland was below $1 \mathrm{~m}$. In pine savanna, foliage in the layers of 4-15 m was sparse but foliage cover below $1 \mathrm{~m}$ was high. Pine woodland had well-developed vegetation layers that were evenly distributed from the ground to the $10-15 \mathrm{~m}$ layer. The vertical profile of foliage cover for hemlock forest was similar to that of pine woodland, but hemlock forest had more foliage in the layers above $15 \mathrm{~m}$. Spruce forest had a bimodal distribution of foliage cover; the layers above $15 \mathrm{~m}$ and below $0.5 \mathrm{~m}$ had dense foliage cover.

\subsection{Bird community composition}

We registered 17,883 records from 46 species during the field counts. Of these, 37 species were resident, breeding species with at least 3 records (Table 2). In addition, there were two migrant species (Turdus chrysolaus, Zoothera aurea), one nocturnal species (Strix aluco), one altitudinal migrant (Troglodytes troglodytes), and five transient species (Dendrocopos canicapillus, Cuculus poliocephalus, Hypsipetes leucocephalus, Spizixos semitorques, Cettia fortipes).

Bird community composition differed in the five vegetation types (Table 2). The species with highest density in both 

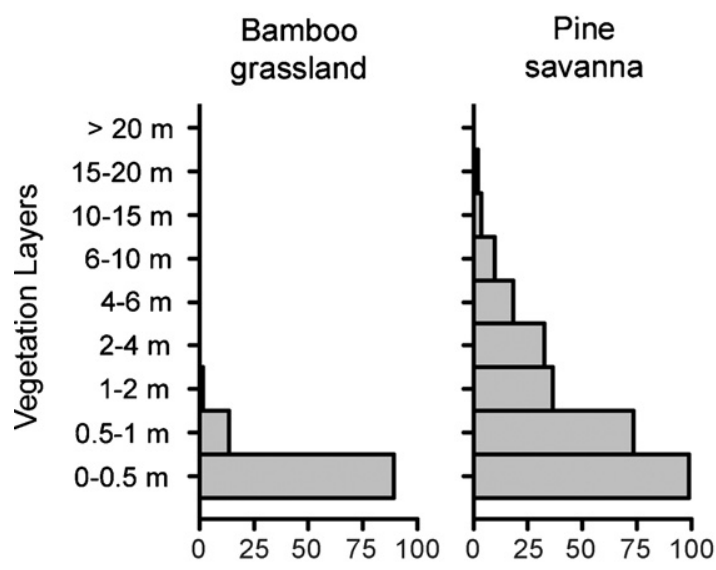
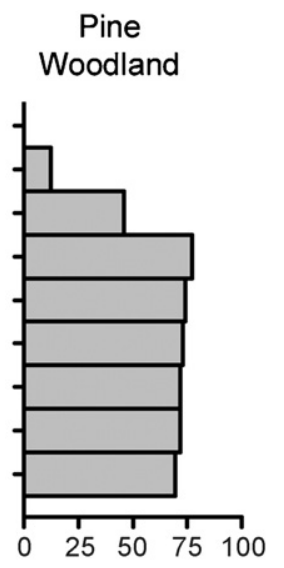

Foliage Cover (\%)
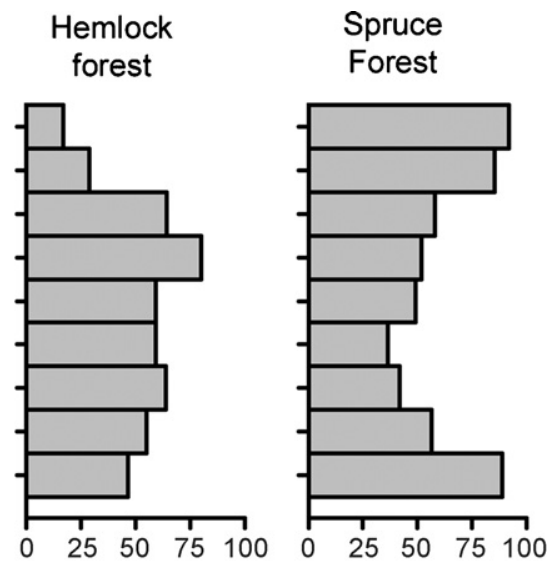

Fig. 2. The vertical profile of foliage cover in bamboo grassland, pine savanna, pine woodland, hemlock forest, and spruce forest.

bamboo grassland and pine savanna were Cettia acanthizoides, Alcippe cinereiceps and B. alishanensis. In pine woodland, Regulus goodfellowi, A. cinereiceps, and C. acanthizoides dominated. In hemlock forest and spruce forest, $R$. goodfellowi, A. cinereiceps, Yuhina brunneiceps, and Muscicapa ferruginea were abundant.

All bird species occurring in early and intermediate successional stages were also present in late successional forests (Table 2). The spruce forest had all but one of the 37 breeding species and had 6 species that were not recorded in other vegetation types.

\subsection{Bird guild structure}

The foraging substrates, foraging tactics, and food items of the 37 local breeding species varied considerably (Table 3). Most species were insectivores that glean prey from a variety of substrates. A total of 10 foraging guilds were identified using cluster analysis (Fig. 3). The guilds were: carnivore (1 species), ground omnivore (3), ground insectivore (2), ground herbivore (2), shrub insectivore (9), tree insectivore (12), tree frugivore (2), bole gleaner (1), bole pecker (2), and aerial insectivore (3).

Hemlock forest and spruce forests had 10 and 9 guilds, respectively, and were dominated by tree insectivores $(58.1 \%$, $58.2 \%)$ and shrub insectivores $(27.6 \%, 18.9 \%)$ (Table 4$)$. Pine woodland and pine savanna both had six guilds, dominated by shrub insectivores $(52.0 \%, 72.9 \%)$ and tree insectivores $(39.1 \%, 16.1 \%)$. Four guilds (carnivore, bole gleaner, bole pecker, and aerial insectivore) were absent from pine woodland and pine savanna. Bamboo grassland only had four guilds and, as the pine savanna and pine woodland, the shrub insectivores (78.6\%) dominated.

The abundance of insectivorous guilds positively correlated with the foliage cover of the vertical layers that they forage. The proportion of shrub insectivores at each station positively correlated with ground foliage cover in simple linear regression analyses $\left(r^{2}=0.88, p<0.001\right)$. The proportion of tree insectivores at each station was positively correlated with the total foliage cover of the canopy and sub-canopy layers $\left(r^{2}=0.90, p<0.001\right)$. The total density of bole peckers and bole gleaners also were significantly and positively correlated with snag basal area $\left(r^{2}=0.29, p=0.01\right)$ at each station, however the amount of variation attributed to snag basal area was relatively small.

\subsection{Analysis of bird community characteristics}

Bird species diversity, bird species richness, total bird density, and total bird biomass all increased with successional stage and peaked in spruce forest (Table 2). Stepwise forward multiple regression (criterion for inclusion and exclusion, $p<0.05$ ) was applied to evaluate the statistical explanatory power of all the 18 habitat attributes on bird species diversity, total bird density, and total bird biomass. Foliage height diversity was significantly and positively correlated with bird species diversity and explained $69.2 \%$ of the variance in bird species diversity $(p<0.001)$. All the other 17 habitat attributes were not significantly correlated with the residuals of bird species diversity $(p>0.05)$ once the effects of foliage height diversity had been removed. Total foliage cover was significantly and positively correlated with total bird density $\left(r^{2}=0.85, p<0.001\right)$ and total bird biomass $\left(r^{2}=0.83\right.$, $p<0.001)$. The other 17 habitat attributes were not significantly correlated with the residuals of total bird density and total bird biomass $(p>0.05)$ once the effects of total foliage cover had been justified.

\subsection{Ordination of bird communities and habitat selection}

The species composition data of bird communities at the 22 sampling stations were analyzed using DCA. The 22 stations fell into 5 groups, based on vegetation type (Fig. 4). Cluster analysis of the bird species density data also placed the sampling stations into the same five groups (data not shown).

The first DCA axis was significantly correlated with most habitat variables (Table 5). Vegetation height $(r=0.94)$, total basal area of trees $(r=0.92)$, and canopy cover $(r=0.89)$ were most highly correlated with the first axis. In general, the first axis represented the increase in tree size with successional stage. The second DCA axis was significantly correlated with 
Table 2

The average density (mean \pm S.D.) (No./ha) of 37 species of breeding birds and bird community characteristics in the five vegetation types

\begin{tabular}{|c|c|c|c|c|c|c|}
\hline English name & Scientific name & Bamboo grassland & Pine savanna & Pine woodland & Hemlock forest & Spruce forest \\
\hline Mikado Pheasant ${ }^{1,2}$ & Syrmaticus mikado & - & - & - & - & $0.02 \pm 0.02$ \\
\hline Ashy Woodpigeon ${ }^{3}$ & Columba pulchricollis & - & $0.02 \pm 0.02$ & $0.04 \pm 0.03$ & $0.03 \pm 0.01$ & $0.19 \pm 0.03$ \\
\hline Himalayan Cuckoo & Cuculus saturatus & - & $0.02 \pm 0.04$ & $0.03 \pm 0.01$ & $0.21 \pm 0.11$ & $0.18 \pm 0.09$ \\
\hline Collared Owlet ${ }^{3}$ & Glaucidium brodiei & - & - & - & $0.03 \pm 0.03$ & - \\
\hline White-backed Woodpecker ${ }^{3}$ & Dendrocopos leucotos & - & - & - & $0.06 \pm 0.05$ & $0.06 \pm 0.05$ \\
\hline Grey-headed Woodpecker ${ }^{1}$ & Picus canus & - & - & - & - & $0.01 \pm 0.01$ \\
\hline Eurasian Nutcracker ${ }^{3}$ & Nucifraga caryocatactes & - & - & - & $0.73 \pm 0.28$ & $0.14 \pm 0.03$ \\
\hline Large-billed Crow & Corvus macrorhynchos & - & $0.04 \pm 0.03$ & $0.01 \pm 0.01$ & $0.11 \pm 0.10$ & $0.02 \pm 0.02$ \\
\hline Eurasian Jay & Garrulus glandarius & - & - & - & - & $0.03 \pm 0.03$ \\
\hline Green-backed Tit & Parus monticolus & - & - & - & $0.21 \pm 0.23$ & $0.34 \pm 0.17$ \\
\hline Coal Tit & Parus ater & $0.08 \pm 0.04$ & $0.10 \pm 0.09$ & $0.30 \pm 0.11$ & $1.58 \pm 0.40$ & $2.00 \pm 0.25$ \\
\hline Black-throated Tit & Aegithalos concinnus & - & $0.87 \pm 0.78$ & $1.84 \pm 0.69$ & $0.30 \pm 0.35$ & $1.06 \pm 1.23$ \\
\hline Yellowish-bellied Bush Warbler & Cettia acanthizoides & $3.10 \pm 0.35$ & $4.52 \pm 0.43$ & $5.21 \pm 0.67$ & $2.24 \pm 0.81$ & $0.95 \pm 0.47$ \\
\hline Taiwan Bush Warbler ${ }^{2}$ & Bradypterus alishanensis & $2.46 \pm 0.45$ & $1.88 \pm 0.34$ & $1.24 \pm 0.48$ & $0.53 \pm 0.24$ & $0.59 \pm 0.18$ \\
\hline Rufous-faced Warbler & Abroscopus albogularis & - & - & - & $0.02 \pm 0.03$ & $0.21 \pm 0.18$ \\
\hline Scaly-breasted Wren-Babbler & Pnoepyga albiventer & - & - & $0.19 \pm 0.11$ & $0.25 \pm 0.19$ & $0.65 \pm 0.20$ \\
\hline Rufous-capped Babbler & Stachyris ruficeps & $0.09 \pm 0.05$ & $0.14 \pm 0.11$ & $0.74 \pm 0.16$ & $0.62 \pm 0.07$ & $0.76 \pm 0.09$ \\
\hline White-whiskered Laughing-thrush ${ }^{2}$ & Garrulax morrisonianus & $0.90 \pm 0.26$ & $0.92 \pm 0.15$ & $1.14 \pm 0.10$ & $1.03 \pm 0.27$ & $0.96 \pm 0.12$ \\
\hline Steere's Liocichla ${ }^{2}$ & Liocichla steerii & - & - & - & $0.27 \pm 0.23$ & $1.09 \pm 0.30$ \\
\hline Taiwan Barwing ${ }^{2,3}$ & Actinodura morrisoniana & - & - & $0.13 \pm 0.11$ & $0.72 \pm 0.41$ & $1.18 \pm 0.70$ \\
\hline Streak-throated Fulvetta & Alcippe cinereiceps & $2.79 \pm 0.62$ & $4.92 \pm 0.66$ & $8.16 \pm 1.75$ & $6.43 \pm 0.37$ & $3.57 \pm 1.15$ \\
\hline Grey-cheeked Fulvetta & Alcippe morrisonia & - & - & $0.51 \pm 0.56$ & $1.18 \pm 0.41$ & $3.68 \pm 0.88$ \\
\hline White-eared Sibia ${ }^{2}$ & Heterophasia auricularis & $0.05 \pm 0.04$ & $0.02 \pm 0.03$ & $0.02 \pm 0.03$ & $0.01 \pm 0.02$ & $0.24 \pm 0.11$ \\
\hline Taiwan Yuhina $^{2}$ & Yuhina brunneiceps & $0.37 \pm 0.14$ & $0.52 \pm 0.48$ & $3.23 \pm 0.44$ & $5.36 \pm 0.89$ & $5.60 \pm 0.43$ \\
\hline Golden Parrotbill $^{3}$ & Paradoxornis verreauxi & - & $0.45 \pm 0.32$ & $3.21 \pm 1.51$ & - & $0.93 \pm 1.52$ \\
\hline Flamecrest $^{2}$ & Regulus goodfellowi & $0.27 \pm 0.31$ & $1.27 \pm 0.64$ & $11.31 \pm 4.76$ & $16.19 \pm 2.59$ & $20.37 \pm 3.76$ \\
\hline Eurasian Nuthatch & Sitta europaea & - & - & - & $0.73 \pm 0.90$ & $0.14 \pm 0.16$ \\
\hline Taiwan Whistling Thrush ${ }^{2}$ & Myophonus insularis & - & - & - & - & $0.08 \pm 0.09$ \\
\hline White-browed Shortwing & Brachypteryx montana & $0.05 \pm 0.04$ & $0.12 \pm 0.20$ & $1.74 \pm 0.50$ & $0.88 \pm 0.51$ & $1.88 \pm 0.37$ \\
\hline White-browed Bush Robin ${ }^{1}$ & Luscinia indica & $0.06 \pm 0.07$ & $0.69 \pm 0.52$ & $1.79 \pm 0.78$ & $2.47 \pm 0.23$ & $2.19 \pm 0.20$ \\
\hline Collared Bush Robin ${ }^{2}$ & Luscinia johnstoniae & $1.51 \pm 0.58$ & $0.80 \pm 0.38$ & $1.68 \pm 0.49$ & $1.11 \pm 0.77$ & $1.94 \pm 0.65$ \\
\hline Ferruginous Flycatcher & Muscicapa ferruginea & - & - & - & $0.27 \pm 0.31$ & $7.43 \pm 3.80$ \\
\hline Snowy-browed Flycatcher ${ }^{3}$ & Ficedula hyperythra & - & - & - & - & $0.22 \pm 0.18$ \\
\hline Vivid Niltava & Niltava vivida & - & - & - & - & $0.28 \pm 0.19$ \\
\hline Vinaceous Rosefinch & Carpodacus vinaceus & $0.13 \pm 0.19$ & $0.07 \pm 0.07$ & $1.65 \pm 0.38$ & $0.86 \pm 0.33$ & $0.86 \pm 0.38$ \\
\hline Brown Bullfinch $^{3}$ & Pyrrhula nipalensis & - & - & - & $0.06 \pm 0.07$ & $0.12 \pm 0.10$ \\
\hline Grey-headed Bullfinch ${ }^{3}$ & Pyrrhula erythaca & $0.09 \pm 0.07$ & $0.33 \pm 0.11$ & $0.43 \pm 0.18$ & $0.64 \pm 0.16$ & $0.22 \pm 0.10$ \\
\hline Total bird density (No./ha) & & $11.95^{\mathrm{a}}$ & $17.76^{\mathrm{b}}$ & $44.71^{\mathrm{c}}$ & $44.40^{\mathrm{c}}$ & $60.11^{\mathrm{d}}$ \\
\hline Bird species richness & & $14^{\mathrm{a}}$ & $20^{\mathrm{b}}$ & $23^{c}$ & $30^{\mathrm{d}}$ & $36^{\mathrm{e}}$ \\
\hline Bird species diversity & & $1.89^{\mathrm{a}}$ & $2.15^{\mathrm{b}}$ & $2.38^{\mathrm{c}}$ & $2.30^{\mathrm{c}}$ & $2.50^{\mathrm{d}}$ \\
\hline Total biomass (g/ha) & & $188.2^{\mathrm{a}}$ & $267.9^{\mathrm{b}}$ & $536.9^{c}$ & $612.8^{\mathrm{d}}$ & $819.3^{\mathrm{e}}$ \\
\hline
\end{tabular}

The values that are not significantly different $(p>0.05)$ are indicated by shared superscript letters.

${ }^{1}$ Rare in Taiwan.

2 Endemic to Taiwan.

${ }^{3}$ Uncommon in Taiwan.

proportion of ground foliage cover $(r=-0.69)$ and foliage height diversity $(r=0.66)$ (Table 5). The third axis was significantly correlated with only a few habitat variables, all of which were more highly correlated with the first axis or second axis.

The 37 breeding bird species were well separated on the biplot of the first two DCA axes (Fig. 5). Most species that forage in shrubs appear on the left side of first axis. This corresponds to their preferred habitats, those with fewer trees. Most species that forage in the upper layers of the forest appear right of the first axis. Species that only occurred in late successional stages (aerial insectivores, bole peckers, and bole gleaner) also appear right of the first axis. Species that forage on the ground were spread widely on the biplot.

\section{Discussion}

\subsection{Bird species composition in vegetation at different successional stages}

We found that late successional forests contained all the observed breeding bird species in the Tatachia area. No bird species were restricted to the early or intermediate successional stages. This finding differs from the results of many previous studies in temperate areas (e.g., Hutto, 1995; Imbeau et al., 1999; Hunter et al., 2001; Litvaitis, 2001; Herrando et al., 2003; Venier and Pearce, 2005; Paquet et al., 2006). In addition, all the dominant plant species in early and intermediate successional stages also occurred in late successional forests. Because 
Table 3

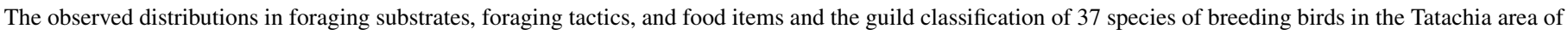
Taiwan

\begin{tabular}{|c|c|c|c|c|c|c|c|c|c|c|c|c|c|c|}
\hline \multirow[t]{2}{*}{ Species } & \multirow[t]{2}{*}{ Guild $^{1}$} & \multirow[t]{2}{*}{$n^{2}$} & \multicolumn{5}{|c|}{ Foraging substrates (\%) } & \multicolumn{4}{|c|}{ Foraging tactics $(\%)$} & \multicolumn{3}{|c|}{ Food items (\%) } \\
\hline & & & Ground & Shrub & Leaves & Bole & Air & Flycatch & Hawk & Glean & Peck & Plant & Invertebrates & Vertebrates \\
\hline Mikado Pheasant & GO & 2 & 100 & 0 & 0 & 0 & 0 & 0 & 0 & 100 & 0 & 70 & 30 & 0 \\
\hline Ashy Woodpigeon & $\mathrm{TF}$ & 3 & 0 & 0 & 100 & 0 & 0 & 0 & 0 & 100 & 0 & 100 & 0 & 0 \\
\hline Himalayan Cuckoo & TI & 2 & 0 & 0 & 90 & 10 & 0 & 0 & 20 & 80 & 0 & 0 & 100 & 0 \\
\hline Collared Owlet & $\mathrm{CA}$ & 0 & 20 & 0 & 80 & 0 & 0 & 0 & 100 & 0 & 0 & 0 & 0 & 100 \\
\hline White-backed Woodpecker & $\mathrm{BP}$ & 26 & 0 & 0 & 0 & 100 & 0 & 0 & 0 & 0 & 100 & 0 & 100 & 0 \\
\hline Grey-headed Woodpecker & $\mathrm{BP}$ & 2 & 0 & 0 & 0 & 100 & 0 & 0 & 0 & 0 & 100 & 0 & 100 & 0 \\
\hline Eurasian Nutcracker & TI & 5 & 0 & 0 & 80 & 20 & 0 & 0 & 0 & 100 & 0 & 30 & 70 & 0 \\
\hline Large-billed Crow & GO & 30 & 100 & 0 & 0 & 0 & 0 & 0 & 0 & 100 & 0 & 30 & 30 & 40 \\
\hline Eurasian Jay & TI & 20 & 0 & 0 & 70 & 30 & 0 & 0 & 20 & 80 & 0 & 30 & 50 & 20 \\
\hline Green-backed Tit & TI & 21 & 0 & 0 & 90 & 10 & 0 & 0 & 0 & 100 & 0 & 0 & 100 & 0 \\
\hline Coal Tit & TI & 47 & 4 & 0 & 96 & 0 & 0 & 0 & 0 & 100 & 0 & 0 & 100 & 0 \\
\hline Black-throated Tit & TI & 33 & 0 & 5 & 85 & 10 & 0 & 0 & 0 & 100 & 0 & 0 & 100 & 0 \\
\hline Yellowish-bellied Bush Warbler & SI & 116 & 0 & 46 & 34 & 20 & 0 & 0 & 0 & 100 & 0 & 0 & 100 & 0 \\
\hline Taiwan Bush Warbler & SI & 6 & 50 & 50 & 0 & 0 & 0 & 0 & 0 & 100 & 0 & 0 & 100 & 0 \\
\hline Rufous-faced Warbler & TI & 3 & 0 & 20 & 80 & 0 & 0 & 0 & 0 & 100 & 0 & 0 & 100 & 0 \\
\hline Scaly-breasted Wren-Babbler & SI & 5 & 40 & 60 & 0 & 0 & 0 & 0 & 0 & 100 & 0 & 0 & 100 & 0 \\
\hline Rufous-capped Babbler & SI & 2 & 0 & 90 & 10 & 0 & 0 & 0 & 0 & 100 & 0 & 20 & 80 & 0 \\
\hline $\begin{array}{l}\text { White-whiskered } \\
\text { Laughing-thrush }\end{array}$ & SI & 62 & 15 & 41 & 18 & 26 & 0 & 0 & 0 & 100 & 0 & 22 & 78 & 0 \\
\hline Steere's Liocichla & SI & 13 & 0 & 70 & 30 & 0 & 0 & 0 & 0 & 100 & 0 & 25 & 75 & 0 \\
\hline Taiwan Barwing & TI & 64 & 0 & 0 & 50 & 50 & 0 & 0 & 0 & 100 & 0 & 27 & 73 & 0 \\
\hline Streak-throated Fulvetta & SI & 131 & 2 & 73 & 17 & 8 & 0 & 0 & 0 & 100 & 0 & 0 & 100 & 0 \\
\hline Grey-cheeked Fulvetta & TI & 21 & 0 & 24 & 66 & 10 & 0 & 0 & 0 & 100 & 0 & 15 & 85 & 0 \\
\hline White-eared Sibia & TI & 5 & 0 & 0 & 80 & 20 & 0 & 0 & 0 & 100 & 0 & 40 & 60 & 0 \\
\hline Taiwan Yuhina & TI & 91 & 0 & 2 & 94 & 4 & 0 & 0 & 0 & 100 & 0 & 12 & 88 & 0 \\
\hline Golden Parrotbill & SI & 77 & 0 & 100 & 0 & 0 & 0 & 0 & 0 & 100 & 0 & 0 & 100 & 0 \\
\hline Flamecrest & TI & 85 & 0 & 0 & 90 & 10 & 0 & 0 & 0 & 100 & 0 & 0 & 100 & 0 \\
\hline Eurasian Nuthatch & BG & 43 & 0 & 0 & 17 & 83 & 0 & 0 & 0 & 100 & 0 & 0 & 100 & 0 \\
\hline Taiwan Whistling Thrush & GI & 1 & 100 & 0 & 0 & 0 & 0 & 0 & 10 & 90 & 0 & 0 & 80 & 20 \\
\hline White-browed Shortwing & SI & 5 & 40 & 60 & 0 & 0 & 0 & 0 & 0 & 100 & 0 & 0 & 100 & 0 \\
\hline White-browed Bush Robin & GI & 30 & 83 & 0 & 0 & 17 & 0 & 0 & 0 & 100 & 0 & 0 & 100 & 0 \\
\hline Collared Bush Robin & GI & 55 & 73 & 0 & 0 & 27 & 0 & 0 & 11 & 89 & 0 & 0 & 100 & 0 \\
\hline Ferruginous Flycatcher & FI & 27 & 0 & 0 & 4 & 0 & 96 & 96 & 0 & 4 & 0 & 0 & 100 & 0 \\
\hline Snowy-browed Flycatcher & FI & 7 & 0 & 20 & 20 & 0 & 60 & 80 & 0 & 20 & 0 & 0 & 100 & 0 \\
\hline Vivid Niltava & FI & 22 & 0 & 0 & 0 & 0 & 100 & 100 & 0 & 0 & 0 & 0 & 100 & 0 \\
\hline Vinaceous Rosefinch & $\mathrm{GH}$ & 25 & 48 & 32 & 20 & 0 & 0 & 0 & 0 & 100 & 0 & 100 & 0 & 0 \\
\hline Brown Bullfinch & $\mathrm{TF}$ & 26 & 0 & 0 & 100 & 0 & 0 & 0 & 0 & 100 & 0 & 100 & 0 & 0 \\
\hline Grey-headed Bullfinch & GH & 28 & 54 & 32 & 14 & 0 & 0 & 0 & 0 & 100 & 0 & 100 & 0 & 0 \\
\hline
\end{tabular}

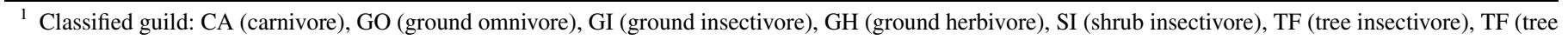
frugivore), BG (bole gleaner), BP (bole pecker), and FI (aerial insectivore).

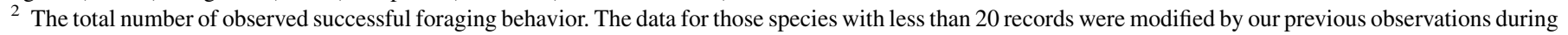
breeding seasons in the study site.

all sampling stations in the late successional stages were located in large, round patches (at least $3 \mathrm{~km}^{2}$ ) and at least $200 \mathrm{~m}$ away from vegetation edge, we think the primary reason that late successional stages included all the species from earlier stages is because forest fires and large-area early successional stages are relatively new and rare to the Tatachia area and, possibly, the mountain areas of Taiwan.

Taiwan is an island with high annual precipitation, high humidity, and rugged terrain. For example, the Alishan weather station (2413 $\mathrm{m}$ a.s.1.), about $7 \mathrm{~km}$ from the study site, had an average annual precipitation of $3802 \mathrm{~mm}$ and average relative humidity of $86.5 \%$ from 1971 to 2000 . Even during the driest month at the Alishan weather station (January), the average precipitation was $88 \mathrm{~mm}$ and the average relative humidity was
$80 \%$. Given the high precipitation and humidity, natural fire should be relatively rare and limited in the study site and in the mountain areas of Taiwan. Among the 1454 forest fires recorded in the National Forests of Taiwan from 1963 to 2004, fewer than $1 \%$ of the fires started naturally and the rest were started by human activities (e.g., farming, hunting, recreation and arson) (Lin, 1992; Hwang and Lin, 2005).

Based on several studies of stable isotope ratios in soil organic matter from the Tatachia area, most, if not all, of the study site was forested between 500 and 2500 years ago (Chiang et al., 2004; Hsueh, 2005). Tsukada (1966, 1967) analyzed the pollen records in Sun-Moon-Lake, about $42 \mathrm{~km}$ from our study site. He found that, during the past 40,000 years, Gramineae were abundant only in the last 4000 years. Studies in 


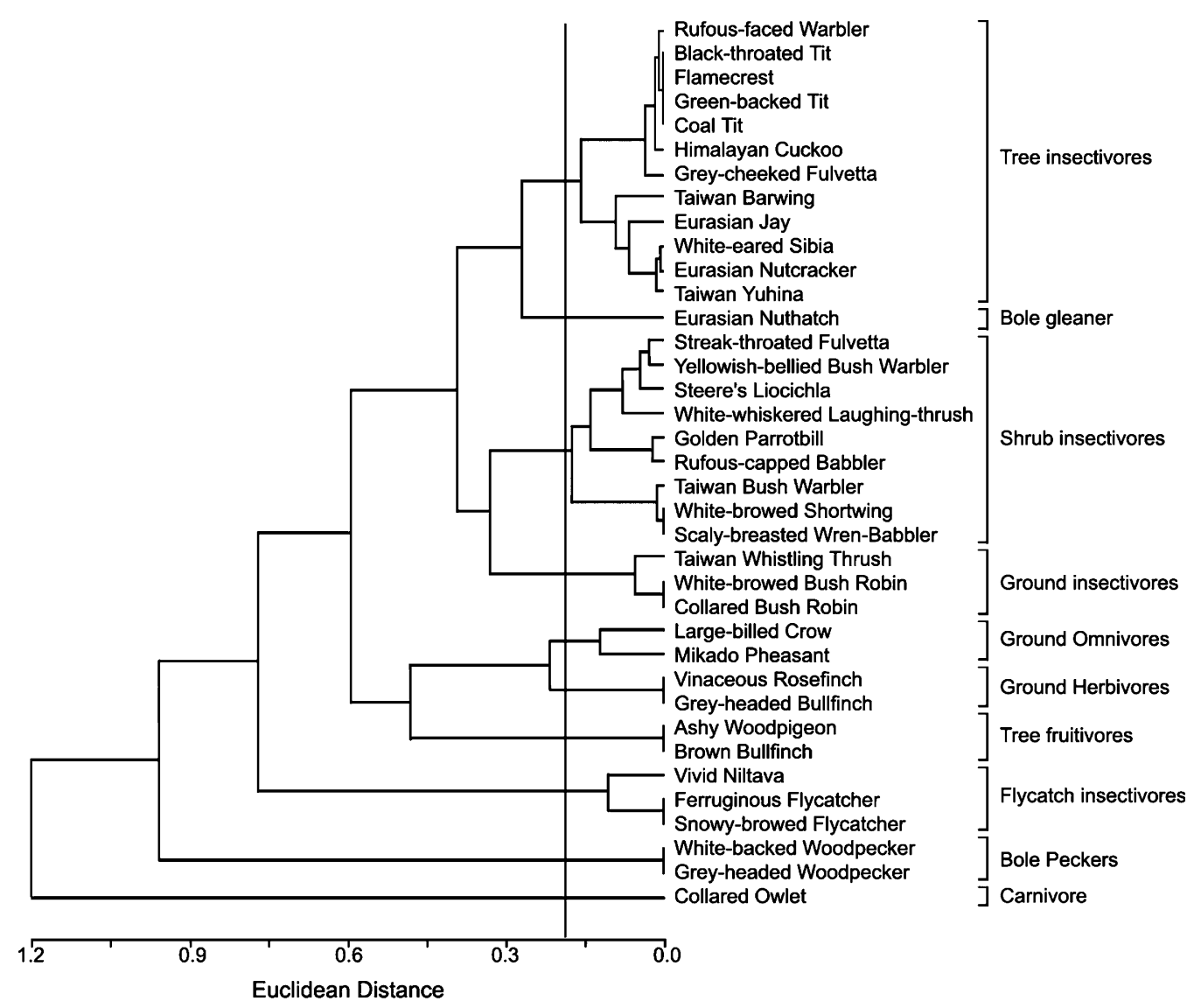

Fig. 3. The 37 species of breeding birds were grouped into 10 ecological guilds based on foraging behavior.

Tatachia and Sun-Moon-Lake suggest that forest fires were rare in the study area before A.D. 1000, when indigenous people first settled this area. Thus, birds may have had insufficient time and opportunity to become specialists in early or intermediate successional stages generated by wildfire.

Typhoons and landslides are other major natural disturbances occurring in the forests in Taiwan. Although typhoons damage forests, they seldom initiate primary succession of vegetation. Unless typhoons cause large areas of landslides, most trees are still alive after typhoons and the plant species composition is not changed dramatically. Landslides sweep away most trees and start primary succession of vegetation. However, the early successional stages caused by landslides usually consist of a narrow band that spans the elevational gradient. Most plant and animal species in the mountain areas of Taiwan are distributed within a narrow elevation range. The early successional stages regenerated in landslide areas often differed greatly with elevation. This further limits the area of early and intermediate successional stages and the chance that birds will become specialists of them.

Maintaining land mosaics of various vegetation types at different successional stages, which usually results in higher species richness, has been a guiding principle of habitat management for conserving biodiversity (reviewed in Tews et al., 2004; Bennett et al., 2006; Parr and Andersen, 2006). We found that some shrub foragers were more abundant in the early

Table 4

The relative abundance (\%) of bird guilds in the five vegetation types

\begin{tabular}{lccccc}
\hline Guild & Bamboo grassland & Pine savanna & Pine woodland & Hemlock forest \\
\hline Carnivore & 0 & 0 & 0 & 0.1 & 0.2 \\
Ground omnivore & 0 & 0.2 & 0.1 & 8.1 & 0.1 \\
Ground insectivore & 13.1 & 8.4 & 7.8 & 3.4 & 7.0 \\
Ground herbivore & 1.9 & 2.2 & 0.9 & 27.6 & 1.8 \\
Shrub insectivore & 78.6 & 16.9 & 52.0 & 58.1 & 0.2 \\
Tree insectivore & 6.4 & 0.1 & 0.1 & 1.6 & 0.1 \\
Tree frugivore & 0 & 0 & 0 & 0.1 & 0.2 \\
Bole gleaner & 0 & 0 & 0 & 0.1 & 0.1 \\
Bole pecker & 0 & 0 & 0 & & 13.2 \\
Aerial insectivore & 0 & & & \\
\hline
\end{tabular}




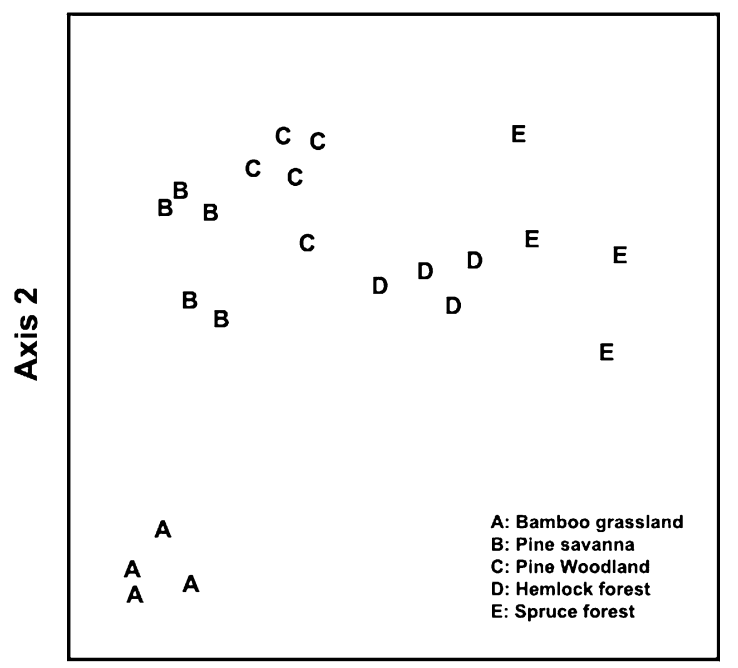

Axis 1

Fig. 4. The distribution of the 22 sampling stations on the DCA biplot correlated closely with the successional stage of the vegetation in which each station was located. The first DCA axis represents the increase in tree size with successional stage, and the second DCA axis represents the decrease in proportion of ground foliage.

successional stages, indicating this habitat has special value for shrub foragers. However, if species that occurred in early or intermediate successional stages are common in late successional habitats, there may be no need to actively manage for early or intermediate successional habitats in areas where disturbance was historically rare. Instead, we should maintain large area of late successional stages, which are often threatened with destruction in developing countries (Soulé, 1991).

\subsection{Abundance of bird ecological guilds in different successional stages}

More than $90 \%$ of the birds in this study were insectivores. Omnivores and herbivores were rare. In general, most of the terrestrial bird species in the world are insectivores. Insectivores are usually dominant in coniferous forests (FernandezJuricic, 2000), which often have fewer plant species and subsequently provide fewer types of food for omnivores and herbivores than other vegetation types.

The abundance of foliage insectivores (species that prey on insects on foliage) is correlated with the distribution of foliage (Yuan et al., 2005). We found that shrub insectivores were dominant in bamboo grassland and pine savanna, where most foliage occurs as herbs and shrubs, and were less common in pine woodland, hemlock forest, and spruce forest. Likewise, tree insectivores dominated in late successional stages, in which most forest foliage was on sub-canopy and canopy trees.

Aerial insectivores (three species of flycatchers) were present only in late successional forests. Flycatchers usually perch on solitary twigs and catch flying insects in the air. This foraging behavior and their abundance are highly correlated with increasingly diverse foliage structure (Holmes and Recher, 1986). The hemlock forests and spruce forests in this study area
Table 5

Correlations between the habitat variables and the first three axes of the DCA

\begin{tabular}{|c|c|c|c|}
\hline & Axis 1 & Axis 2 & Axis 3 \\
\hline Length (standard deviation) & 1.607 & 0.679 & 0.669 \\
\hline Eigenvalue & 0.220 & 0.022 & 0.013 \\
\hline \multicolumn{4}{|l|}{ Abiotic attributes } \\
\hline Altitude (m) & $-0.75^{*}$ & $-0.60^{*}$ & 0.37 \\
\hline Aspect & 0.02 & $0.56^{*}$ & -0.37 \\
\hline \multicolumn{4}{|l|}{ Physiognomic attributes } \\
\hline Vegetation height $(\mathrm{m})$ & $0.94^{*}$ & 0.38 & -0.16 \\
\hline Herb cover $(\%)$ & -0.36 & 0.03 & 0.18 \\
\hline Shrub cover $(\%)$ & 0.30 & $0.59^{*}$ & -0.52 \\
\hline Sub-canopy cover $(\%)$ & $0.82^{*}$ & 0.35 & -0.20 \\
\hline Canopy cover $(\%)$ & $0.89^{*}$ & 0.32 & -0.30 \\
\hline Total foliage cover $(\%)$ & $0.86^{*}$ & $0.54^{*}$ & -0.49 \\
\hline Proportion of ground foliage (\%) & $-0.71^{*}$ & $-0.69^{*}$ & $0.62^{*}$ \\
\hline Tree density (No./ha) & $0.73^{*}$ & 0.37 & -0.18 \\
\hline Mean DBH $(\mathrm{cm})$ & 0.29 & 0.44 & -0.47 \\
\hline $\mathrm{CV}$ of $\mathrm{DBH}(\mathrm{cm})$ & $0.75^{*}$ & 0.39 & -0.05 \\
\hline Total BA of trees $\left(\mathrm{m}^{3} / \mathrm{ha}\right)$ & $0.92^{*}$ & 0.42 & -0.19 \\
\hline Total BA of snags $\left(\mathrm{m}^{3} / \mathrm{ha}\right)$ & $0.73^{*}$ & 0.21 & -0.12 \\
\hline Foliage height diversity & $0.78^{*}$ & $0.66^{*}$ & $-0.59^{*}$ \\
\hline \multicolumn{4}{|l|}{ Floristic attributes } \\
\hline Tree species richness & $0.84^{*}$ & 0.36 & -0.22 \\
\hline Tree species diversity & 0.44 & $0.61^{*}$ & -0.48 \\
\hline Proportion of broadleaf tree $(\%)$ & $0.83^{*}$ & 0.33 & 0.17 \\
\hline
\end{tabular}

had taller vegetation, more total foliage volume, and a more even vertical distribution of foliage. Thus, these forests provide more perching twigs and, possibly, more insects for the flycatchers that other vegetation types.

Many studies (e.g., Hutto, 1995; Schieck and Song, 2006) have reported that bole peckers and bole gleaners are more common in burned areas. Forest fires often create plenty of snags and logs, which provide more foraging substrates and nesting sites for bole specialists (Hutto, 1995; Imbeau et al., 1999). We found the bole peckers and bole gleaners were only present in late successional stages and were not found in the early and intermediate successional stages. This is likely because the bamboo grassland in the study site burned at least four times in the past 70 years. The frequent fires in the bamboo grassland prevent the existence of snags, as found in our results. Additionally, the high temperature and humidity of the study site resulted in relatively rapid decomposition of snags. As a result, few bole peckers or bole gleaners recruit to burned areas. Snags only become common in mature forests after some trees die of competition or disease.

\subsection{Relationships between bird community characteristics and vegetation structure}

We found that species diversity and the total density of breeding birds increased with time of succession. However, some studies (e.g., Imbeau et al., 1999; Keller et al., 2003; Pons and Wendenburg, 2005) reported that bird species diversity and total density peaked $0-12$ years following fires. Because there have not been any recent fires in the Tatachia area, the youngest 


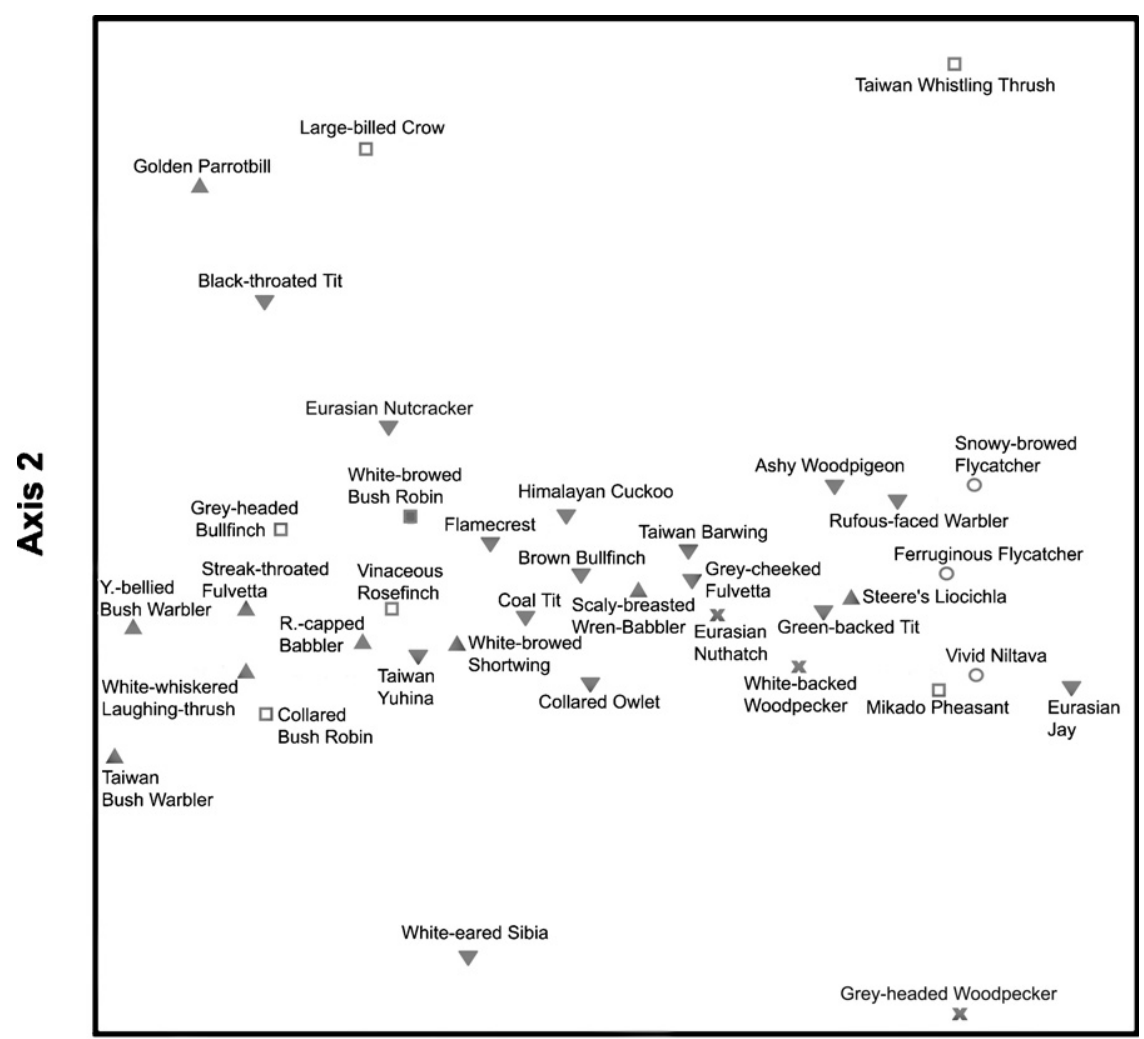

\section{Axis 1}

Fig. 5. The 37 species of breeding birds were separated on the biplot of the first two DCA axes ( $(\boldsymbol{\nabla})$ species that forage mainly in trees, ( $(\mathbf{\Delta})$ species that forage mainly in shrubs, $(\square)$ species that forage mainly on ground, $(\bigcirc)$ species that forage for prey in the air, $(\times)$ bole pecker or bole gleaner). The first DCA axis represents the increase in tree size with successional stage, and the second DCA axis represents the decrease in proportion of ground foliage.

vegetation we could investigate was the 11-year-old bamboo grassland that was burned in January 1993. Nevertheless, during the breeding seasons of 1993 (T.-S. Ding, unpublished data) and 1996 (Fang and Yuan, 1999), we surveyed the bird community of this bamboo grassland with similar sampling effort, investigators, and locations of sampling stations. Bird species richness and density in 1993 ( 8 species, 5.07 No./ha) and in 1996 (9 species, 6.80 No./ha) were lower than in this study (14 species, 11.95 No./ha). Thus, within this vegetation type, species richness and total density increased with time since fire.

We found that late successional stages contained higher bird species richness and diversity, total density, and total biomass. Habitat structure heterogeneity is thought to be a primary factor determining the species richness and diversity of terrestrial birds (Keller et al., 2003; Lee et al., 2004; Díaz et al., 2005; Schwab et al., 2006). Where vegetation structure is more heterogeneous (either horizontally or vertically), more types of foraging opportunities exist, and bird species that specialize on specific layers or plant species are more likely to occur. In this study, most bird species had only one foraging tactic and limited their foraging to one or two substrates. Only a few species foraged on three or more substrates. Late successional forests exhibited greater diversification in vertical structure and greater tree species richness and had higher bird species richness and species diversity. The higher total bird density and biomass of a given area is usually associated with higher primary productivity (Ding et al., 2005). We did not directly measure primary productivity of the sampling stations but we found that foliage cover was highly correlated with total bird density. This correlation held for overall vegetation type and for specific foliage layers. Compared with other successional stages, the late successional forests had lower ground foliage cover but higher overall foliage cover. As a result, the total density and biomass of birds foraging in shrubs and on the ground was lower, but overall bird total density and biomass was higher. Therefore, when managing habitats, increasing the structural complexity of the vegetation should attract more bird species and increasing foliage volume should support a greater number of birds.

\section{Acknowledgements}

The authors thank Alan Warneke, Fu-Hsiung Hsu, Bao-Sen Shieh, and two anonymous referees for their helpful suggestions on the earlier drafts. This research was supported by the National Science Council, Taiwan, Republic of China (NSC922621-B-002-009).

\section{References}

Attiwill, P.M., 1994. The disturbance of forest ecosystems-the ecological basis for conservative management. For. Ecol. Manage. 63, 247-300. 
Barbaro, L., Rossi, J.P., Vetillard, F., Nezan, J., Jactel, H., 2007. The spatial distribution of birds and carabid beetles in pine plantation forests: the role of landscape composition and structure. J. Biogeogr. 34, 652-664.

Bennett, A.F., Radford, J.Q., Haslem, A., 2006. Properties of land mosaics: implications for nature conservation in agricultural environments. Biol. Conserv. 133, 250-264.

Brawn, J.D., Robinson, S.K., Thompson III, F.R., 2001. The role of disturbance in the ecology and conservation of birds. Annu. Rev. Ecol. Syst. 32, 251276.

Chiang, P.N., Wang, M.K., Chiu, C.Y., King, H.B., Hwong, J.L., 2004. Changes in the grassland-forest boundary at Ta-Ta-Chia long term ecological research (LTER) site detected by stable isotope ratios of soil organic matter. Chemosphere 54, 217-224.

Cochrane, M.A., Schulze, M.D., 1999. Fire as a recurrent event in tropical forests of the eastern Amazon: effects on forest structure, biomass, and species composition. Biotropica 31, 2-16.

DeGraaf, R.M., Yamasaki, M., 2003. Options for managing early-successional forest and shrubland bird habitats in the Northeastern United States. For. Ecol. Manage. 185, 179-191.

Díaz, I.A., Armesto, J.J., Reid, S., Sieving, K.E., Willson, M.F., 2005. Linking forest structure and composition: avian diversity in successional forests of Chiloé Island. Chile. Biol. Conserv. 123, 91-101.

Dickinson, E.C. (Ed.), 2003. The Howard and Moore Complete Checklist of the Birds of the World. third ed. Princeton University Press, Princeton, USA.

Ding, T.-S., Yuan, H.-W., Geng, S., Lin, Y.-S., Lee, P.-F., 2005. Energy flux, body size, and density in relation to bird species richness along an elevational gradient in Taiwan. Global Ecol. Biogeogr. 14, 299-306.

Fang, C.-Y., Yuan, H.-W., 1999. Effects of pine forest fire to the bird community in the Tatachia Area, Nantou County, Taiwan. Q. J. Chin. For. 32, 1-12.

Fernandez-Juricic, E., 2000. Forest fragmentation affects winter flock formation of an insectivorous guild. Ardea 88, 235-241.

Green, K., Sanecki, G., 2006. Immediate and short-term responses of bird and mammal assemblages to a subalpine wildfire in the Snowy Mountains, Australia. Austral. Ecol. 31, 673-681.

Herrando, S., Brotons, L., Llacuna, S., 2003. Does fire increase the spatial heterogeneity of bird communities in Mediterranean landscapes? Ibis 145, 307-317.

Holmes, R.T., Recher, H.F., 1986. Search tactics of insectivorous birds foraging in an Australia eucalypt (Eucalyptus) forest. Auk 103, 515-530.

Hsueh, Y.-H., 2005. Using stable carbon isotope and black carbon to infer the possible major vegetation types dynamics in Tatachia area, central Taiwan. Master Thesis. National Taiwan University, Taipei, Taiwan.

Hunter, W.C., Buehler, D.A., Canterbury, R.A., Confer, J.L., Hamel, P.B., 2001. Conservation of disturbance-dependent birds in eastern North America. Wildl. Soc. Bull. 29, 440-455.

Hutto, R.L., 1995. Composition of bird communities following stand-replacement fires in Northern Rocky Mountain (U.S.A.) conifer forests. Conserv. Biol. 9, 1041-1058.

Hwang, C.Y., Lin, C.-C., 2005. Analysis of forest fires in Taiwan national forests. Q. J. Chin. For. 38, 449-464.

Imbeau, L., Savard, J.P.L., Gagnon, R., 1999. Comparing bird assemblages in successional black spruce stands originating from fire and logging. Can. J. Zool. 77, 1850-1860.

Keller, J.K., Richmond, M.E., Smith, C.R., 2003. An explanation of patterns of breeding bird species richness and density following clearcutting in northeastern USA forests. For. Ecol. Manage. 174, 541-564.

Krebs, C.J., 1989. Ecological Methodology. Harper and Row, New York, USA.

Lee, P.-F., Ding, T.-S., Hsu, F.-S., Geng, S., 2004. Bird species richness in Taiwan: distribution on gradients of elevation, primary productivity, and urbanization. J. Biogeogr. 31, 307-314.
Lin, C.-C., 1992. Analysis of fires in national forests in Taiwan (1963-1991). Bull. Taiwan For. Res. Inst. 7, 169-178.

Linder, P., Elfving, B., Zackrisson, O., 1997. Stand structure and successional trends in virgin boreal forest reserves in Sweden. For. Ecol. Manage. 98, 17 33.

Litvaitis, J.A., 2001. Importance of early successional habitats to mammals in eastern forests. Wildl. Soc. Bull. 29, 466-473.

McCune, B., Mefford, M.J., 1999. Multivariate Analysis of Ecological Data, version 4.25. MjM Software, Gleneden Beach, USA.

Oppel, S., 2006. Long-term changes of a coastal bird breeding community on a small island-does natural succession compromise conservation values? Biodivers. Conserv. 14, 3407-3422.

Paquet, J.-Y., Vandevyvre, X., Delahaye, L., Rondeux, J., 2006. Bird assemblages in a mixed woodland-farmland landscape: the conservation value of silviculture-dependant open areas in plantation forest. For. Ecol. Manage. 227, 59-70.

Parr, C.L., Andersen, A.N., 2006. Patch mosaic burning for biodiversity conservation: a critique of the pyrodiversity paradigm. Conserv. Biol. 20, $1610-1619$.

Pons, R., Wendenburg, C., 2005. The impact of fire and forest conversion into savanna on the bird communities of West Madagascan dry forests. Anim. Conserv. 8, 183-193.

Rasmussen, P.C., Round, P.D., Dickinson, E.C., Rozendaal, F.G., 2000. A new bush-warbler (Sylviidae, Bradypterus) from Taiwan. Auk 117, 279-289.

Reynolds, R.T., Scott, J.M., Nussbaum, R.A., 1980. A variable circular-plot method for estimating bird numbers. Condor 82, 309-313.

Sarà, M., Bellia, E., Milazzo, A., 2006. Fire disturbance disrupts co-occurrence patterns of terrestrial vertebrates in Mediterranean woodlands. J. Biogeogr. $33,843-852$.

Schieck, J., Song, S.J., 2006. Changes in bird communities throughout succession following fire and harvest in boreal forests of western North America: literature review and meta-analyses. Can. J. For. Res. 36, 1299-1318.

Schwab, F.E., Simon, N.P.P., Sinclair, A.R.E., 2006. Bird-vegetation relationships in Southern British Columbia. J. Wildl. Manag. 70, 189-197.

Shiu, H.-J., Ding, T.-S., Sheu, J.-E., Lin, R.-S., Koh, C.-N., Lee, P.-F., 2005. Morphological characters of bird species in Taiwan. Taiwania 50, 80-92.

Shiu, H.-J., Lee, P.F., 2003. Assessing avian point-count duration and sample size using species accumulation functions. Zool. Stud. 42, 357-367.

Soulé, M.E., 1991. Conservation-tactics for a constant crisis. Science 253, $744-750$.

Su, H.-J., 1984. Studies on the climate and vegetation types of the natural forests in Taiwan (II): altitudinal vegetation zones in relation to temperature gradient. Q. J. Chin. For. 17, 57-73.

Su, H.-J., 1987. Forest habitat factors and their quantitative assessment. Q. J. Chin. For. 20, 1-14.

Tews, J., Brose, U., Grimm, V., Tielborger, K., Wichmann, M.C., Schwager, M., Jeltsch, F., 2004. Animal species diversity driven by habitat heterogeneity/ diversity: the importance of keystone structures. J. Biogeogr. 31, 79-92.

Tsukada, M., 1966. Late Pleistocene vegetation and climate in Taiwan (Formosa). Proc. Natl. Acad. Sci. U.S.A. 55, 543-548.

Tsukada, M., 1967. Vegetation in subtropical Formosa during the Pleistocene and the Holocene. Paleogeogr. Paleoclimatol. Paleoecol. 3, 49-64.

Venier, L.A., Pearce, J.L., 2005. Boreal bird community response to jack pine forest succession. For. Ecol. Manage. 217, 19-36.

Wang, D.P., Ji, S.Y., Chen, F.P., Xing, F.W., Peng, S.L., 2006. Diversity and relationship with succession of naturally regenerated southern subtropical forests in Shenzhen, China and its comparison with the zonal climax of Hong Kong. For. Ecol. Manage. 222, 384-390.

Yuan, H.-W., Ding, T.-S., Hsieh, H.-I., 2005. Short-term responses of animal communities to thinning in a Cryptomeria japonica (Taxodiaceae) plantation in Taiwan. Zool. Stud. 44, 393-402. 